\title{
Management of complex lipid abnormalities with a fixed dose combination of simvastatin and extended release niacin
}

\author{
Jennifer G Robinson \\ University of lowa, lowa City, \\ IA, USA
}

Correspondence: Jennifer G Robinson Lipid Research Clinic, 200 Hawkins Drive SE $223 \mathrm{GH}$, lowa City, IA 52242, USA Tel + I 3 I $93845040 / 5003$

Fax +I 3193845045

Email jennifer-g-robinson@uiowa.edu

\begin{abstract}
ER niacin combined with simvastatin provides an additional option for achieving LDL-C and non-HDL-C goals for cardiovascular prevention, with greater efficacy in those with triglyceride levels $>200 \mathrm{mg} / \mathrm{dL}$. ER niacin $1000 \mathrm{mg}$ combined with simvastatin $20 \mathrm{mg}$ reduced LDL-C by $6 \%$, non-HDL-C by $7 \%$, and triglycerides by $13 \%$, and raised HDL-C by $11 \%$ compared to simvastatin $20 \mathrm{mg}$ alone. The $2000 \mathrm{mg}$ dose combined with simvastatin 20 to $40 \mathrm{mg}$ raised reduced LDL-C by $7 \%$ to $24 \%$, non-HDL-C by $16 \%$ to $28 \%$, and triglycerides by $23 \%$ to $34 \%$, and increased HDL-C by $18 \%$ to $22 \%$ compared to similar dose simvastatin therapy. While cardiovascular risk is reduced in proportion to the magnitude of LDL-C lowering, the additive benefit of raising HDL-C and lowering triglycerides remains to be determined. ER niacin-simvastatin is reasonably well tolerated, with a $<7 \%$ discontinuation rate due to flushing in patients who used aspirin or non-steroidal anti-inflammatory medications as needed. However, drop-out rates were high in both the simvastatin and ER niacin-simvastatin treatment groups in both the 24- and 52-week studies. The safety profile of the combination appears to be similar to that of niacin and simvastatin used as monotherapies. Results of ongoing morbidity/mortality trials of ER niacin added to statin therapy are eagerly awaited.
\end{abstract}

Keywords: simvastatin, niacin, fixed-dose, dyslipidemia

One extended-release (ER) niacin-simvastatin formulation is available in the US and another formulation has been approved in Europe, with approval pending in the US. Simcor ${ }^{\circledR}$ (Abbott Laboratories, North Chicago, Illinois, USA) is the combination of ER niacin (Niaspan ${ }^{\circledR}$; Abbott Laboratories, North Chicago, Illinois, USA) and simvastatin (Zocor ${ }^{\circledR}$, Merck Inc., White House Station, New Jersey) which was approved by the US Food and Drug Administration (FDA) February, 2008. ER niacin-simvastatin is indicated to reduce elevated total cholesterol, low density lipoprotein cholesterol (LDL-C), apolipoprotein (apo) B, non-high density lipoprotein cholesterol (non-HDL-C), or triglycerides, or to increase HDL-C in patients with primary hypercholesterolemia and mixed dyslipidemia when treatment with simvastatin monotherapy or niacin extended-release monotherapy is considered inadequate. ${ }^{1}$ ER niacin-simvastatin is also indicated to reduce triglycerides in patients with hypertriglyceridemia (Frederickson type IV hyperlipidemia) when treatment with simvastatin monotherapy or niacin ER monotherapy is considered inadequate.

Another combination of ER niacin with simvastatin and laropiprant, a compound that decreases flushing, MK-524A (previously called Cordaptive ${ }^{\circledR}$ ) (Merck, Inc., White House Station, New Jersey, USA), was not approved by the FDA in April, 2008 although it was approved in European countries. The reason for non-approval 
have not been reported, although is likely related to the inclusion of laropiprant. Laropiprant is a potent $\mathrm{PGD}_{2}$ DP-1 receptor antagonist shown to reduce moderate to severe niacin-induced cutaneous vasodilatation without affecting lipid-modifying efficacy. ${ }^{2}$ Laropiprant could have harmful off-target effects that may counteract beneficial effects of lipid changes on atherosclerotic disease. Laropiprant is also an antagonist of the thromoboxane $\mathrm{A}_{2}$ receptor although little effect on platelet aggregation assays or bleeding time has been observed. ${ }^{3}$ The major metabolite of $\mathrm{PGD}_{2}$ is a potent endogenous PPAR $\gamma$ activator. Activation of PPAR $\gamma$ via $\mathrm{PGD}_{2}$ with niacin has been shown to stimulate ABCA1-mediated efflux of cholesterol from macrophages. ${ }^{4}$ Whether efforts to minimize cutaneous symptoms will influence these pathways is unresolved. Moreover, the DP-1 receptor is found in numerous tissues and the specificity of laropiprant for epidermal Langherhans also remains to be established. It is not clear whether approval of the Merck product awaits the results of the ongoing Treatment of HDL to Reduce the Incidence of Vascular Events (HPS-2 THRIVE), which is comparing the effect of ER niacin plus laropiprant-simvastatin to simvastatin alone on major cardiovascular events in 20,000 subjects. ${ }^{5}$

Published data are available only for the ER niacinsimvastatin coformulation so will be the focus of this review. The pharmacology, efficacy and safety of ER niacin with simvastatin will be presented first, followed by a discussion of the clinical context for this drug combination.

\section{Pharmacology}

Niacin exposure from ER niacin-simvastatin has the same pharmacologic properties as ER niacin used as monotherapy. ${ }^{1}$ Simvastatin levels were $23 \%$ to $41 \%$ higher from ER niacin-simvastatin than from simvastatin as monotherapy. Mechanisms of action, metabolism, and excretion are otherwise comparable to those for each drug used as monotherapy. Adverse effects of niacin and simvastatin therapy are discussed below.

Simvastatin undergoes extensive first pass metabolism and is hydrolyzed to the corresponding active $\beta$-hydroxyacid form, a potent inhibitor of 3-hydroxy-3-methylglutarylcoenzyme A (HMG CoA) reductase, the rate-limiting step in cholesterol synthesis. ${ }^{6} \mathrm{HMG}-\mathrm{CoA}$ reductase inhibition reduces tissue and plasma cholesterol levels, which results in upregulation of the expression of LDL receptors in the liver and extrahepatic tissues, thereby enhancing removal of the cholesterol-rich apolipoproteins LDL-C, very low density lipoprotein cholesterol (VLDL-C), and VLDL remnants from plasma. Simvastatin is predominantly metabolized by the cytochrome P450 isoform (CYP) 3A4, and to a lesser degree CYP3A5, CYP2C8, and by glucuronidation. Hepatic uptake of simvastatin is facilitated by organic ion transporting polypeptide 1B1, polymorphisms of which have been associated with increases plasma simvastatin levels and propensity to myopathy. ${ }^{7}$ Simvastatin has $13 \%$ urinary excretion and $60 \%$ biliary excretion. Drug interactions and adverse effects of simvastatin are discussed below.

Niacin is a form of vitamin B3 that in pharmacologic doses has beneficial effects on multiple lipid parameters. Niacin undergoes extensive first pass metabolism in the liver where it is rapidly converted to the active form nicotinamide adenine dinucleotide (NAD) in the NAD coenzyme system. ${ }^{1}$ Niacin is not metabolized through the same pathways as statins, and is excreted in urine. Niacin has few important drug interactions although it is extensively bound to cholestyramine.

Niacin lowers the level of very low density lipoprotein cholesterol (VLDL-C), the precursor to LDL-C, through a variety of mechanisms, only some of which have been elucidated. ${ }^{8,9}$ Activation of adipocyte $G$ protein-coupled nicotinic acid receptor GPR109A (HM74A in humans) results in inhibition of hormone-sensitive lipase, reduced triglyceride hydrolysis, and reduced flux of free fatty acids from adipose to the liver. Decreased fatty acid synthesis and esterification reduces triglyceride synthesis. Increased lipoprotein lipase activity may increase the rate of chylomicron triglyceride removal from plasma. Reductions in intrahepatic triglyceride availability taken together with increased catabolism of apolipoprotein B, results in decreased assembly of apolipoprotein (apo)-B containing proteins VLDL and LDL. ${ }^{10}$ Increased catabolism of VLDL-C also lowers LDL-C levels. Reduced large triglyceride-rich VLDL-C levels result in lower levels of small dense LDL-C. Niacin raises HDL-C by increasing apo A-I synthesis and decreasing HDL-C uptake and removal via the ATP synthase $\beta$-chain, an HDL/ApoA-I receptor for HDL endocytosis in liver cells. ${ }^{10,11}$ Decreased triglyceride synthesis may also increase HDL-C levels. Niacin does not affect the reverse cholesterol transport pathway.

\section{Efficacy}

Three shorter-term efficacy and safety trials comparing ER niacin-simvastatin to simvastatin monotherapy have been published, SEACOAST I and II (24 weeks) and OCEANS (52 weeks) (Table 1). ${ }^{12-14}$ Subjects were selected on the basis of having a non-HDL-C above the goal defined in the third National Cholesterol Education Program Adult Treatment 
Panel (ATP III). About half of subjects were women and most were middle aged (median age 58-60 years). On a lead-in of either simvastatin $20 \mathrm{mg}$ or $40 \mathrm{mg}$, median non-HDL-C levels were 131 to $165 \mathrm{mg} / \mathrm{dL}(3.39-4.27 \mathrm{mmol} / \mathrm{L})$, LDL-C levels were 99 to $118 \mathrm{mg} / \mathrm{dL}(2.56-3.06 \mathrm{mmol} / \mathrm{L}), \mathrm{HDL}-\mathrm{C}$ levels were 41 to $47 \mathrm{mg} / \mathrm{dL}(1.06-1.22 \mathrm{mmol} / \mathrm{L})$, triglyceride levels were 141 to $214 \mathrm{mg} / \mathrm{dL}(1.59-2.42 \mathrm{mmol} / \mathrm{L})$, and Apo B levels were 89 to $103 \mathrm{mg} / \mathrm{dL}$. Adherence rates were $96 \%$ to $98 \%$ in the 24 -week SEACOAST studies and $82 \%$ in the 52-week OCEANS study. Drop-out rates were substantial and unusually high for this type of shorter-term efficacy safety trial. However, the rates in the ER niacin - simvastatin groups (28\%-31\% for the $1000 \mathrm{mg}$ doses, $22 \%-29 \%$ for the $2000 \mathrm{mg}$ doses) did not differ greatly from the simvastatin monotherapy groups $(26 \%-27 \%)$ in the SEACOAST studies.

In SEACOAST I, the addition of ER niacin $1000 \mathrm{mg}$ to simvastatin $20 \mathrm{mg}$ reduced non-HDL-C by another $7 \%$ compared to simvastatin $20 \mathrm{mg}$ plus $50 \mathrm{mg}$ of immediaterelease (IR) niacin added with the intention of maintaining the blind but without lipid-lowering efficacy. LDL-C was reduced by $6 \%$, triglycerides by $13 \%$, and Apo B by $10 \%$, and increased HDL-C by $11 \%$ (Table 1). ${ }^{13}$ (Note: efficacy comparisons in the text were calculated as difference from the simvastatin comparator arm at the end of the treatment period). The addition of ER niacin $2000 \mathrm{mg}$ to simvastatin $20 \mathrm{mg}$ decreased non-HDL-C by another $16 \%$, LDL-C by $7 \%$, triglycerides by $23 \%$, and Apo B by $14 \%$, and increased HDL-C by $18 \%$. Greater reductions in non-HDL-C were observed in those with triglycerides $\geq 200 \mathrm{mg} / \mathrm{dL}$ ( $-9 \%$ on ER niacin $1000 \mathrm{mg}$ and $-19 \%$ compared to simvastatin monotherapy) than those with triglycerides $<200 \mathrm{mg} / \mathrm{dL}$ (-5\% for ER niacin $1000 \mathrm{mg}$ and $-7 \%$ for ER niacin $2000 \mathrm{mg}$ ). A similar blunting of efficacy with lower triglyceride levels was also observed for triglycerides $(-14 \%$ and $-29 \%$ vs $-9 \%$ and $-14 \%)$, and Apo B (-11\% and $-20 \%$ vs $-3 \%$ and $-6 \%)$ but not for HDL-C (+9\% and $+17 \%$ vs $+14 \%$ and $+20 \%$ ). ER niacin-simvastatin appeared to have similar efficacy in women as in men.

In SEACOAST II, when ER niacin $1000 \mathrm{mg}$ was added to simvastatin $40 \mathrm{mg}$ there was no difference in non-HDL-C or LDL-C compared to simvastatin $80 \mathrm{mg}$ (with $50 \mathrm{mg}$ IR niacin), although HDL-C increased by $14 \%$ and triglycerides were reduced by $23 \% .{ }^{12}$ However, ER niacin $2000 \mathrm{mg}$ added to simvastatin $40 \mathrm{mg}$ had greater efficacy for all lipid parameters when compared to simvastatin $80 \mathrm{mg}$. When compared to simvastatin $80 \mathrm{mg}$, non-HDL-C was reduced by an additional $7 \%$, triglycerides by $32 \%$, and Apo B by $10 \%$, and HDL-C was increased by $21 \%$, although LDL-C did not differ. ${ }^{12}$
In the OCEANS study, after a lead-in on simvastatin $40 \mathrm{mg}$, subjects were randomized to receive an 8- or 12-week titration of ER niacin to $2000 \mathrm{mg}$ combined with simvastatin $40 \mathrm{mg} .{ }^{14}$ No difference in tolerability, safety, or efficacy was found and results were pooled for analysis. Compared to baseline after 4 weeks of simvastatin $40 \mathrm{mg}$ therapy, at 24 weeks the addition of ER niacin $2000 \mathrm{mg}$ to simvastatin $40 \mathrm{mg}$ reduced non-HDL-C by an additional $22 \%$, LDL-C by $21 \%$, triglycerides by $30 \%$, and apo B by $20 \%$, and increased HDL-C by $21 \%$ (Table 1 ). A little more than half of subjects completed 52 weeks of followup and slightly greater efficacy for all lipid parameters was observed. The greater efficacy observed in OCEANS was similar to that observed in the SEACOAST studies when the on-treatment lipid levels on $2000 \mathrm{mg}$ ER niacin were compared to baseline levels.

All 3 trials evaluated lipoprotein (a) [Lp(a)]. As shown in Table 1, baseline $\mathrm{Lp}$ (a) levels ranged from 9 to $24 \mathrm{mg} / \mathrm{dL}$ $(0.32-0.86 \mu \mathrm{mol} / \mathrm{L})$. Compared to simvastatin 20 or $40 \mathrm{mg}$ with $50 \mathrm{mg}$ of immediate-release niacin, the addition of ER niacin $1000 \mathrm{mg}$ reduced Lp(a) levels by $9 \%$ to $17 \%$, and the addition of ER niacin $2000 \mathrm{mg}$ reduced Lp(a) levels by an additional $17 \%$ to $21 \%$. When compared to the simvastatin 20 to $40 \mathrm{mg}$ lead-in, $\mathrm{Lp}$ (a) reductions of $21 \%$ to $29 \%$ were observed. Ratios of Apo A-I to Apo B increased by $4 \%$ to $16 \%$ for the ER niacin $1000 \mathrm{mg}$ groups and by $10 \%$ to $30 \%$ for the ER niacin $2000 \mathrm{mg}$ groups compared to simvastatin with $50 \mathrm{mg}$ immediate-release niacin groups. Compared to the simvastatin monotherapy lead-in, the ER niacin $2000 \mathrm{mg}$ dose increased the Apo A-I/B ratio by $22 \%$ to $43 \%$. Commensurate declines of $25 \%$ to $33 \%$ in the total to HDL-C ratio compared to baseline were observed.

The addition of ER niacin 1000 or $2000 \mathrm{mg}$ to simvastatin 20 or $40 \mathrm{mg}$ did not increase the proportion of subjects achieving their NCEP-defined non-HDL-C and LDL-C goals compared to simvastatin 20 or $80 \mathrm{mg}$ monotherapy. ${ }^{12,13}$ Although not a goal established by ATP III, ${ }^{15}$ subjects receiving ER niacin 1000 or $2000 \mathrm{mg}$ with simvastatin $40 \mathrm{mg}$, or ER niacin $2000 \mathrm{mg}$ with simvastatin $20 \mathrm{mg}$ (65\%, $75 \%$, and $70 \%$ respectively) were more likely to achieve an HDL-C $\geq 40 \mathrm{mg} / \mathrm{dL}(1.04 \mathrm{mmol} / \mathrm{L})$ compared to simvastatin 20 or $80 \mathrm{mg}$ ( $45 \%$ and $25 \%$, respectively). Achievement of a triglyceride level $<150 \mathrm{mg} / \mathrm{dL}(1.69 \mathrm{mmol} / \mathrm{L})$, again not a goal established by ATP III, occurred with greater frequently with ER niacin 1000 or $2000 \mathrm{mg}$ with simvastatin $40 \mathrm{mg}$, or ER niacin $2000 \mathrm{mg}$ with simvastatin $20 \mathrm{mg}$, (45\%, 65\%, and $50 \%$, respectively) than with simvastatin 20 or $80 \mathrm{mg}$ (30\% and $15 \%$, respectively). 
Table I ER niacin-simvastatin trials

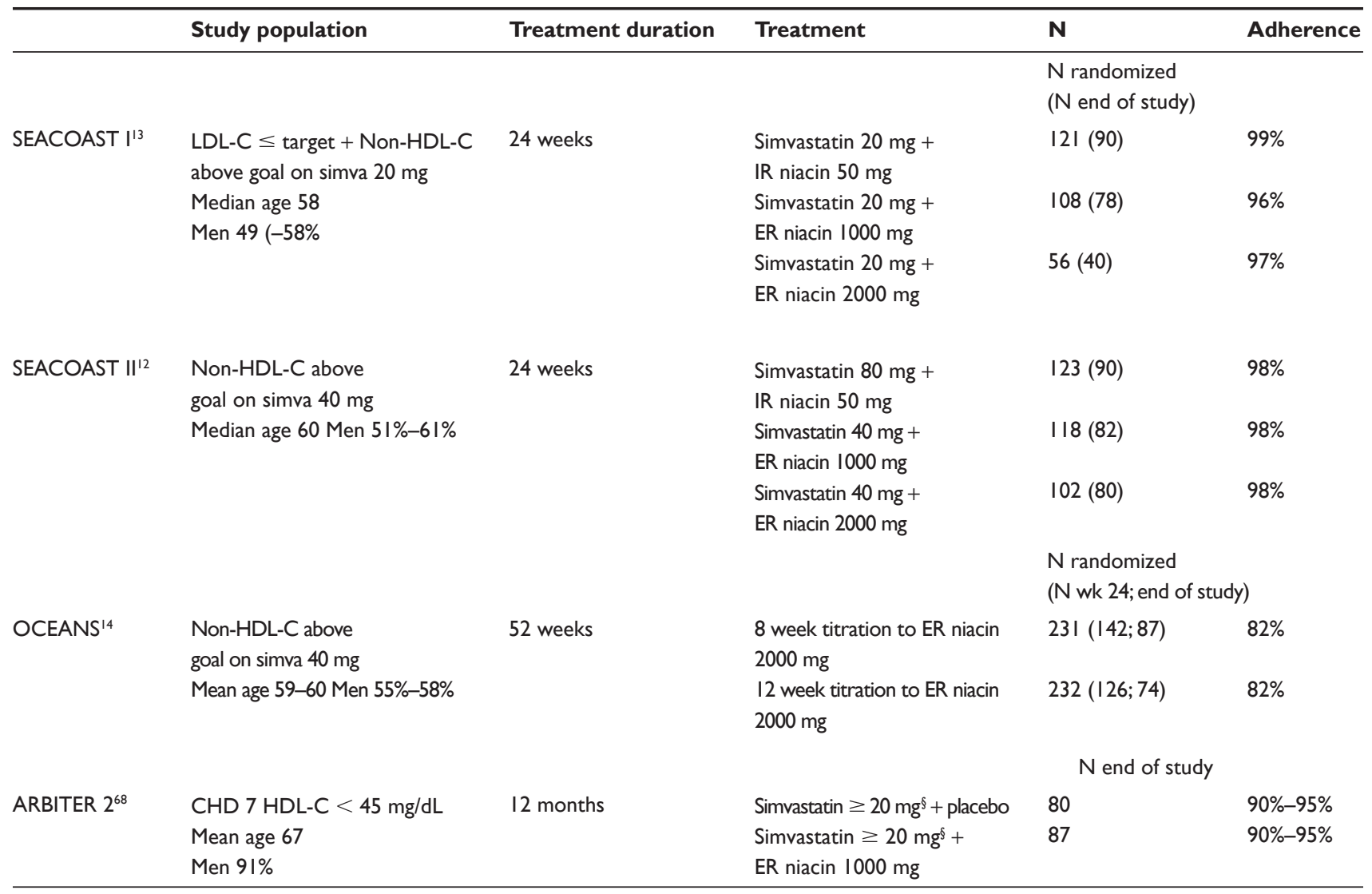

$\$ 93.4 \%$ received simvastatin.

No trials comparing ER niacin-simvastatin to placebo are available to gauge absolute lipid benefits. It is somewhat unclear from the limited data in the 3 trials above whether the addition of ER niacin to simvastatin retains the full effect of both agents on LDL-C. ER niacin $2000 \mathrm{mg}$ lowered LDL-C by $14 \%$ in the ER niacin clinical database, and this reduction was preserved when added to lovastatin $40 \mathrm{mg}$ (Advicor $^{\circledR}$, Abbott Laboratories, North Chicago, Illinois). ${ }^{25}$ It does appear that in patients with non-HDL-C above goals on statin therapy, most of the benefit should be expected in non-HDL-C rather than LDL-C levels, as was observed in the study populations of these $3 \mathrm{ER}$ niacin-simvastatin trials.

\section{Adverse effects}

\section{Flushing}

Niacin-induced flushing of the face and upper body is characterized by redness, warmth, tingling, or itching, and usually lasts an hour or less. Flushing is related to peak serum levels of niacin. ER niacin is absorbed over 8 to 12 hours and peak levels are lower than for immediate release niacin. ${ }^{16}$
Although the proportion of patients who flushed was about the same for ER niacin as for immediate-release niacin, the number of flushing episodes was much lower ( 9 vs 2 flushing events) over a 4 week period after 4 weeks on the $1500 \mathrm{mg}$ dose. ${ }^{17}$ In the 2 trials of the ER niacin and simvastatin 20 or $40 \mathrm{mg}$, ER niacin-simvastin, about $55 \%$ of subjects experienced any flushing with the $1000 \mathrm{mg}$ ER niacin, and up to about $65 \%$ experienced any flushing with the $2000 \mathrm{mg}$ ER niacin dose (Table 2). Serious flushing and flushing resulting in discontinuation occurred in only 4 to $7 \%$ of those receiving $1000 \mathrm{mg}$ ER niacin and $6 \%$ to $11 \%$ of those receiving the $2000 \mathrm{mg}$ dose.

Niacin binds to adipocyte and macrophage GPR109A (HM74A) to induce release of prostaglandin $\mathrm{D}_{2}\left(\mathrm{PGD}_{2}\right)$ by epidermal Langherhans cells. ${ }^{18} \mathrm{PGD}_{2}$ acts locally on capillary smooth muscle cells via the $\mathrm{PGD}_{2}$ receptor (DP1) to induce cutaneous capillary vasdilation. Niacin may also increase prostaglandin $\mathrm{E}_{2}$, thromboxane $\mathrm{B}_{2}$, and leukotriene synthesis. Pretreatment with aspirin $325 \mathrm{mg}$ or other non-steroidal ant-inflammatory agents that inhibit prostaglandin release 
Table I (Continued)

\begin{tabular}{llllllll}
\hline Non-HDL-C & LDL-C & HDL-C & Triglyceride & Lp(a) & Apo B & Apo A-I/ B ratio & Total/ HDL-C ratio \\
\hline \multicolumn{7}{c}{ Baseline after 4 week simvastatin $20 \mathrm{mg}$ lead-in in $\mathrm{mg} / \mathrm{dL}$ (Median change from simvastatin $20 \mathrm{mg}$ lead-in - ITT) } \\
$157(-7 \%)$ & $115(-7 \%)$ & $43(7 \%)$ & $209(-15 \%)$ & $15(-8 \%)$ & $101(-4 \%)$ & $1.2(11 \%)$ & $5(-10 \%)$ \\
$165(-14 \%)$ & $118(-13 \%)$ & $41(18 \%)$ & $210(-27 \%)$ & $12(-17 \%)$ & $103(-14 \%)$ & $1.3(27 \%)$ & $5(-21 \%)$ \\
$160(-23 \%)$ & $112(-14 \%)$ & $41(25 \%)$ & $214(-38 \%)$ & $9(-25 \%)$ & $96(-18 \%)$ & $1.3(41 \%)$ & $5(31 \%)$
\end{tabular}

Baseline after 4-week simvastatin $40 \mathrm{mg}$ lead-in in $\mathrm{mg} / \mathrm{dL}$ (Median change from simvastatin $40 \mathrm{mg}$ lead-in)

$\begin{array}{llllllll}131(-10 \%) & 99(-13 \%) & 47(-1 \%) & 1410 \% & 190 \% & 89(-9 \%) & 1.5(12 \%) & 3.8(-5 \%) \\ 136(-11 \%) & 105(-9 \%) & 44(15 \%) & 147(-23 \%) & 20(-17 \%) & 90(-10 \%) & 1.5(16 \%) & 4.1(-16 \%) \\ 143(-17 \%) & 109(-12 \%) & 46(22 \%) & 156(-32 \%) & 23(-21 \%) & 92(-14 \%) & 1.4(22 \%) & 4.2(-25 \%)\end{array}$

Baseline after 4 week simvastatin $40 \mathrm{mg}$ lead-in in $\mathrm{mg} / \mathrm{dL}$ (Median change from simvastatin $40 \mathrm{mg}$ lead-in - ITT at 24 weeks [only subjects completing 52 weeks])

\begin{tabular}{|c|c|c|c|c|c|c|c|}
\hline $\begin{array}{l}|4|(-23 \%) \\
{[-25 \%]}\end{array}$ & $\begin{array}{l}\text { II I (-22\%) } \\
{[-20 \%]}\end{array}$ & $\begin{array}{l}45(22 \%) \\
{[27 \%]}\end{array}$ & $\begin{array}{l}145(-33 \%) \\
{[-40 \%]}\end{array}$ & $\begin{array}{l}24(-25 \%) \\
{[-29 \%]}\end{array}$ & $\begin{array}{l}94(-22 \%) \\
{[-25 \%]}\end{array}$ & $\begin{array}{l}\text { I.4 (36\%) } \\
\text { [43\%] }\end{array}$ & $\begin{array}{l}4.2(-28 \%) \\
{[-30 \%]}\end{array}$ \\
\hline$|4|(-2 \mid \%)$ & $110(-20 \%)$ & $45(20 \%)$ & $152(-27 \%)$ & $21(-21 \%)$ & $94(-17 \%)$ & I.4 (36\%) & $4.2(-27 \%)$ \\
\hline$[-28 \%]$ & {$[-24 \%]$} & {$[25 \%]$} & {$[-34 \%]$} & {$[-25 \%]$} & {$[-26 \%]$} & {$[43 \%]$} & {$[-33 \%]$} \\
\hline \multicolumn{8}{|c|}{ Baseline in $\mathrm{mg} / \mathrm{dL}$ (Change from baseline in $\mathrm{mg} / \mathrm{dL}$ ) } \\
\hline$|2|(-5 \%)$ & $91(-6 \%)$ & $40(0 \%)$ & $172(-5 \%)$ & & & & $4.0(-3 \%)$ \\
\hline $115(-7 \%)$ & $87(-2 \%)$ & $39(21 \%)$ & $154(-13 \%)$ & & & & $3.95(-17 \%)$ \\
\hline
\end{tabular}

Non-HDL-C = total cholesterol - HDL-C.

Abbreviations: CHD, coronary heart disease; ER, extended release; IQR, interquartile range; IR, immediate release; ITT, intent to treat; LDL-C, low-density lipoprotein cholesterol; Lp(a), lipoprotein (a); Non-HDL-C, non-high-density lipoprotein cholesterol; SR, slow release.

taken 30 to 60 minutes prior to niacin can reduce flushing incidence and intensity by $30 \%$ to $40 \% .^{19,20}$ Tachyphylaxis to $\mathrm{PGD}_{2}$ secretion begins to occur after 1 week of consistent dosing and most patients experience a marked diminution of flushing after 4 weeks and by 1 year most patients report very infrequent or no flushing. ${ }^{16}$ Niacin less commonly causes maculopapular rash and urticaria. Rarely, acanthosis nigricans, hyperpigmentation, and dermopathies may occur.

\section{Liver}

Persistent elevations in hepatic alanine aminotransferase $>3$ times the upper limit of normal, the best index of drugrelated hepatotoxicty, were not reported in the 912 subjects who received ER niacin up to $2000 \mathrm{mg}$ concomitantly with simvastatin 20 to $40 \mathrm{mg}$ over a period of up to 52 weeks. In the ER niacin clinical trial database, none of the 245 subjects receiving doses of 500 to $3000 \mathrm{mg}$ over 17 weeks and $1 \%$ of 1028 subjects receiving ER niacin coformulated with lovastatin had persistent transaminase elevations $>3$ times the upper limit of normal. ${ }^{17}$ Serum alanine aminotransferase should be monitored every 6 to 12 weeks during the first 6 to 12 months of niacin treatment, and every 6 months thereafter. The dose of ER niacin should not exceed $2 \mathrm{~g} /$ day since serious hepatoxicity and fulminant liver failure have been reported with doses of slow or sustained-release nia$\operatorname{cin} \geq 1.5 \mathrm{~g} /$ day. ${ }^{16}$

No safety data are available for ER niacin used with the highest dose $(80 \mathrm{mg})$ of simvastatin. Slightly higher rates of persistent transaminases elevations occur at the highest dose of simvastatin, with $0.9 \%$ having persistent transaminase elevations with $40 \mathrm{mg}$ and $2.1 \%$ with $80 \mathrm{mg}$ over 12 months of treatment. ${ }^{21}$ In long-term morbidity/ mortality studies, persistent transaminase elevations for simvastatin monotherapy are uncommon but dose-related. Moderate dose simvastatin (20-40 mg) has a rate of $<0.5 \%$ over a 5-year period, while simvastatin $80 \mathrm{mg}$ has a rate closer to $1 \%{ }^{22}$ Excessive alcohol intake or a past history of liver disease may also increase the risk of transaminase elevations with simvastatin. Randomized trials have not 


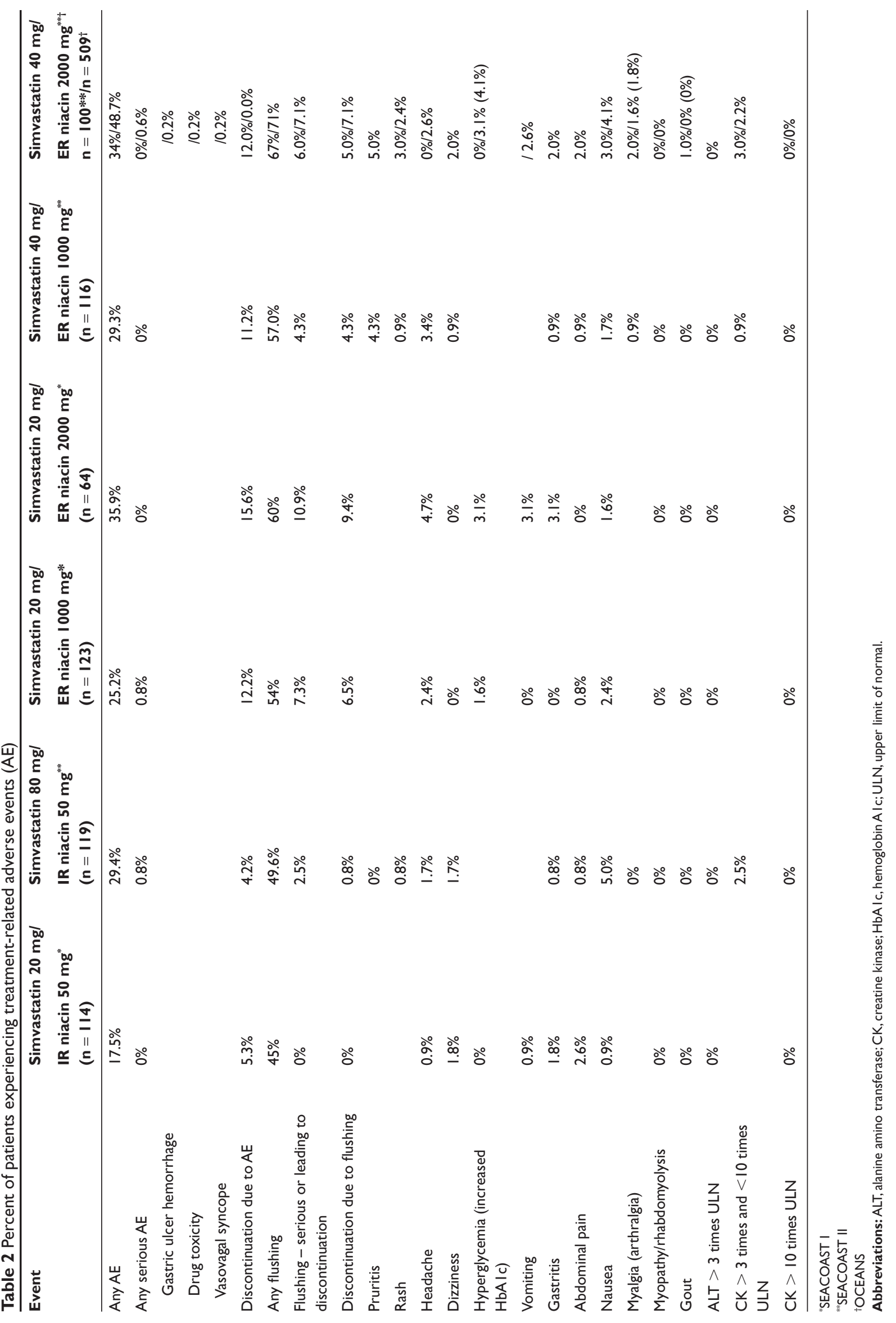


reported any difference in rates of clinical hepatitis (jaundice or other symptoms), hepatic failure, or other evidence of hypersensitivity with simvastatin or any other statin compared to placebo. $^{23}$

\section{Muscle}

The most common form of myotoxicity related to lipid-modifying drugs is myalgia (muscle pain, weakness, or cramps) with normal creatine phosphokinase (CK) levels. Clinically important myopathy is characterized by muscle symptoms and evidence of muscle damage (elevated CK levels), which in its most severe form, rhabdomyolysis, has more extensive muscle damage and is usually associated with renal impairment. ${ }^{24}$ In the 912 subjects in the ER niacin-simvastatin Simcor ${ }^{\circledR}$ clinical trial database, no cases of myopathy, rhabdomyolysis, or CK elevations $>10$ times the upper limit of normal were reported over a period as long as 52 weeks (Table 2). Myalgias were slightly more likely in those receiving simvastatin $40 \mathrm{mg}$ combined with ER niacin $2000 \mathrm{mg}$ with (2\%) than with ER niacin $1000 \mathrm{mg}$ $(0.9 \%)$. No cases of rhabdomyolysis and 1 case of myopathy were reported in 1079 subjects treated with ER niacin and lovastatin $40 \mathrm{mg}$ over a period of up to 2 years. ${ }^{25}$ Rare cases of rhabdomyolysis have been associated with statins used concomitantly with niacin $\geq 1 \mathrm{~g}$ in the Food and Drug Administration Adverse Event Reporting Database. ${ }^{26}$ Indeed, the safety of ER niacin and a statin appears comparable with the safety of each drug used alone.

In the over 20,000 subjects in the 5-year Heart Protection Study (HPS), about $6 \%$ of subjects reported muscle symptoms at a given visit in both the simvastatin and placebo groups ${ }^{27}$ However, this rate may be lower than experienced in clinical practice since $30 \%$ of subjects did not proceed to randomization following a 5-week active run-in period. Myopathy and rhabdomyolysis are very rare with simvastatin monotherapy. In the clinical trial database for simvastatin, 41,050 subjects were treated with simvastatin, of which $26,747(60 \%)$ were treated more than 4 years. Although very uncommon, dose-related increases in the risk of myopathy and rhabdomyolysis occurred at a rate of $0.02 \%$ for $20 \mathrm{mg}$, $0.08 \%$ for $40 \mathrm{mg}$, and $0.53 \%$ for $80 \mathrm{mg}$. ${ }^{21}$ There were 10 cases of myopathy/rhabdomyolysis in the 10,269 subjects allocated to simvastatin $(0.1 \%)$ in HPS, 4 of whom were $>65$ years; 4 cases of myopathy occurred in the placebo group (0.04\%). ${ }^{27}$ It should be emphasized that participants in clinical trials are carefully selected to minimize the potential for toxicity. Much higher rates of rhabdomyolysis have been found when simvastatin has been used in patients with multiple risk factors for myopathy, including concomitant use with gemfibrozil, advanced age, impaired renal function, and serious comorbid conditions. ${ }^{28}$

Inhibitors of CYP3A4 shown to increase serum simvastatin levels include itraconazole, fluconazole, erythromycin, clarithromycin, cyclosporine, danazol, diltiazem, verapamil, amiodarone, grapefruit juice, HIV protease inhibitors, and some antidepressants. In 25,248 patients treated with simvastatin and verapamil, the incidence of myopathy was $0.63 \%$ compared to $0.061 \%$ in those taking simvastatin with another calcium channel blocker. ${ }^{21}$ The fibrate gemfibrozil (Lopid ${ }^{\circledR}$, Pfizer, New York, NY; generic, Watson Pharamceutical, Corona, CA) inhibits the glucuronidation of statins to inactive forms. ${ }^{29}$ Gemfibrozil increases the blood levels of all statins, with the exception of atorvastatin. ${ }^{30,31}$ Fenofibrate (Tricor $^{\circledR}$, Abbott, North Chicago, IL; Lofibra ${ }^{\circledR}$, Gate, Sellerville, PA; Triglide ${ }^{\circledR}$, Sciele, Atlanta, GA) is a weaker inhibitor of glucuronidation and appears to have a lower rate of serious muscle effects when used concomitantly with a statin.

\section{Other adverse effects of ER niacin}

Niacin may worsen insulin resistance, especially in those with impaired fasting glucose or abnormal glucose tolerance. ${ }^{16}$ Patients with fasting glucose levels 100 to $125 \mathrm{mg} / \mathrm{dL}$ may be at increased risk of developing diabetes on niacin and should be encouraged to adhere to healthy lifestyle pattern and undergo careful monitoring. However, since idiosyncratic elevations of glucose may occur in those with normal glucose levels, fasting glucose should be monitored after each dose titration and annually thereafter. Niacin at a dose of approximately $2000 \mathrm{mg}$ has been shown to reduce coronary heart disease (CHD) events in patients with diabetes but may require intensification of diabetic therapy if glucose control worsens. ${ }^{32,33}$ This dose of niacin has also been shown to reduce CHD in those with metabolic syndrome, although diabetes incidence was not reported. ${ }^{34}$ It is of concern that earlier onset of diabetes may increase long-term cardiovascular risk and so long-term trials are needed to evaluate the cost versus benefit in insulin resistant subjects.

Niacin has several other uncommon adverse effects. ${ }^{16}$ Niacin raises uric acid 5\% to $15 \%$. Gout is a relative contraindication to niacin, although allopurinol can be considered for patients with a history of gout whose serum uric acid levels exceed $10 \mathrm{mg} / \mathrm{dL}$. Niacin more than doubles the risk of atrial fibrillation and should be avoided in patients with intermittent atrial fibrillation or other atrial arrhythmias. 
However, niacin is an option for patients with established atrial fibrillation or ventricular arrhythmias. Other adverse effects of niacin include upper gastrointestinal bleeding (niacin is contraindicated only in patients with active peptic ulcer disease), blurred vision (cystoid macular degeneration reported with niacin $>3 \mathrm{~g}$ ), and mildly decreased platelet counts.

\section{Clinical context for ER niacin- simvastatin use}

Statins are the lipid-modifying drugs of choice for cardiovascular risk reduction. Extensive clinical trial data from over 90,000 participants in long-term trials has shown that for each $38 \mathrm{mg} / \mathrm{dL}$ reduction in low-density lipoprotein cholesterol (LDL-C), statins reduce the risk of CHD by $23 \%$ and stroke by $17 \% .{ }^{35}$ Moreover, statins are quite safe in properly selected patients. ${ }^{22}$ Similar magnitudes of CHD risk reduction occur with other therapies that primarily lower LDL-C. ${ }^{36}$ What is the potential role of simvastatin-niacin fixed dose formulations within this context?

\section{LDL-C}

In order to reach the aggressive LDL-C goals of $<100 \mathrm{mg} / \mathrm{dL}$ $(2.59 \mathrm{mmol} / \mathrm{L})$ or $<70 \mathrm{mg} / \mathrm{dL}(1.81 \mathrm{mmol} / \mathrm{L})$ identified in recent guidelines, ${ }^{37,38}$ the majority of patients will require not only a high-dose statin, which may lower LDL-C by up to $50 \%$ to $60 \%$, but the addition of intensive lifestyle changes and/or or one or more drugs. In the Treating to New Targets Trial, on atorvastatin $10 \mathrm{mg}$ more than half of subjects had an LDL-C $>100 \mathrm{mg} / \mathrm{dL}$ and on atorvastatin $80 \mathrm{mg}$, more than half had an LDL-C $>77 \mathrm{mg} / \mathrm{dL} .{ }^{39}$ Only 2 statins lower LDL-C by $\geq 50 \%$ : atorvastatin 40 to $80 \mathrm{mg} /$ day and rosuvastatin 20 to $40 \mathrm{mg} /$ day. $^{40,41}$ Options for achieving an additional approximate $15 \%$ reduction in LDL-C include quadrupling the statin dose, or adding niacin $2 \mathrm{~g}$, bile acid sequestrants, or ezetimibe $10 \mathrm{mg}$. $^{1,6,17,25,42,43}$ Fibrates have variable effects on LDL-C, and may increase levels in patients with elevated triglyceride levels. ${ }^{44-46}$ In general, fenofibrate appears to more effectively lower LDL-C than gemfibrozil, which also has serious safety concerns when used with a statin.

The Ezetimibe and Simvastatin in Hypercholesterolemia Enhances Atherosclerosis Regression (ENHANCE) trial recently brought into question whether the additional LDL-C reduction from ezetimibe will translate into a reduction in cardiovascular events. In ENHANCE, ezetimibe $10 \mathrm{mg}$ added to high dose simvastatin therapy had no significant effect on carotid intimal medial thickness (CIMT) over a 2-year period in 720 subjects with familial hypercholesterolemia (FH). ${ }^{47}$ ENHANCE differed in 2 important ways from the earlier Atorvastatin versus Simvastatin on Atherosclerosis Progression (ASAP) trial which demonstrated regression with atorvastatin $80 \mathrm{mg}$ compared to simvastatin $40 \mathrm{mg}$ in FH subjects. ${ }^{48}$ In ASAP, subjects were required to have a baseline CIMT $>0.7 \mathrm{~mm}$ and few had been treated with aggressive LDL-C-lowering therapy. As would be expected after ASAP, which was conducted by the same investigators, $80 \%$ of subjects in ENHANCE received prior statin therapy and were most likely treated with high dose statins if not ezetimibe as well. Long-term statin therapy stabilizes plaque by depleting lipid content without changing plaque volume. ${ }^{49}$ In the $20 \%$ of ENHANCE subjects who were statin naïve at baseline, there was evidence of less CIMT progression in those receiving ezetimibe. Two major conclusions can be drawn from ENHANCE. First, ENHANCE demonstrated the success of cholesterol-lowering treatment. ENHANCE subjects (mean age 46) had baseline CIMT levels similar to that of an average 32-year-old male with an untreated LDL-C of $134 \mathrm{mg} / \mathrm{dL}$. ${ }^{50}$ Second, lowering LDL-C by another $17 \%$ over a 2-year period in subjects with stabilized plaque had little effect. The findings in ENHANCE are similar to those in the ASAP trial after 2 additional years of follow-up. ${ }^{51}$ For these reasons, Merck cancelled a carotid IMT trial of its ER niacin-simvastatin-laropiprant product. ${ }^{52}$

The Simvastatin and Ezetimibe in Aortic Stenosis (SEAS) trial failed to meet its primary endpoint of a reduction aortic valve disease events and major cardiovascular events. ${ }^{53}$ Simvastatin $40 \mathrm{mg}$ /ezetimibe $10 \mathrm{mg}$ was compared to placebo over 4 years in 1873 subjects with asymptomatic mild to moderate stenosis who did not have an indication for statin therapy. A $22 \%$ reduction in the secondary endpoint of major atherosclerotic events was found with ezetimibe-simvastatin, which lowered LDL-C by $61 \%$. However, more cancers were observed in the ezetimibesimvastatin $(\mathrm{n}=105,11.1 \%)$ than in the placebo group $(\mathrm{n}=70,7.5 \% ; \mathrm{p}=0.01)$, and more cancer deaths $(\mathrm{n}=39$, $4.1 \%$ vs $n=23,2.5 \% ; p=0.05$. No particular type of cancer was predominant. A meta-analysis of 2 additional ongoing ezetimibe-simvastatin versus simvastatin monotherapy trials (SHARP and IMPROVE-IT, total $\mathrm{N}=20,617$ ) found similar rates of cancer in the 2 groups ( $n=313$ vs 326, respectively; risk ratio $0.96,95 \% \mathrm{CI} 0.82-1.12, \mathrm{p}=0.61) .{ }^{54}$ The mean follow-up of subjects in these trials is less than in SEAS. In light of the controversies surrounding the efficacy and safety of ezetimibe, ER niacin remains a reasonable choice 
for additional LDL-C and non-HDL reduction in patients receiving statin therapy.

\section{Non-HDL-C}

The ATP III guidelines identified non-HDL-C as the second target of therapy in patients with triglyceride levels between 200 and $500 \mathrm{mg} / \mathrm{dL}(2.26-5.64 \mathrm{mmol} / \mathrm{L})$. Non-HDL-C is calculated by subtracting HDL-C from total cholesterol and is a measure of circulating atherogenic Apo B-containing apolipoproteins - LDL-C, VLDL-C and intermediate density lipoprotein cholesterol. The non-HDL-C goal is $30 \mathrm{mg} / \mathrm{dL}$ $(0.78 \mathrm{mmol} / \mathrm{L})$ higher than the LDL-C goal. Non-HDL-C is a more accurate predictor of cardiovascular risk than LDL-C, and closely correlates with Apo B levels in patients receiving statin therapy. ${ }^{55}$ Reductions in non-HDL-C from add-on drug therapies to background statin treatment are about $6 \%$ from doubling the statin dose, $12 \%$ from ezetimibe $10 \mathrm{mg}$, and highly variable for fibrates $(+2 \%$ to $-18 \%){ }^{6,42,44,45}$ Bile acid sequestrants are less effective for lowering non-HDL-C $(-5 \%$ to $8 \%$ ) due to their VLDL-C raising effects. ${ }^{43}$ In contrast, the addition of ER niacin $2000 \mathrm{mg}$ to simvastatin can decrease non-HDL-C by $16 \%$ to $28 \%$, in large part due to the increases in HDL-C. ${ }^{13,25}$

\section{HDL-C and triglycerides $<500 \mathrm{mg} / \mathrm{dL}$}

An HDL-C level $<40 \mathrm{mg} / \mathrm{dL}(1.04 \mathrm{mmol} / \mathrm{L})$ was defined as a risk factor for cardiovascular disease by ATP III on the basis of epidemiologic data. However, a treatment goal was not identified due to the lack of clinical trial evidence that pharmacologically raising HDL-C results in a reduction in cardiovascular risk. The method by which HDL-C is raised may be important. Development of torcetrapib was discontinued due to an excess of deaths in a large morbidity/ mortality trial despite a $72 \%$ increase in HDL-C and a $25 \%$ decrease in LDL-C with torcetrapib over atorvastatin therapy alone. ${ }^{56}$ Adverse off-target effects on the renin-angiotensin system and blood pressure elevations have been implicated, although an adverse effect of cholesteryl ester transfer protein inhibition or other effects cannot be excluded.

Similarly, a triglyceride level $<150 \mathrm{mg} / \mathrm{dL}(1.69 \mathrm{mmol} / \mathrm{L})$ was defined as optimal on the basis of epidemiologic data but a treatment target for drug therapy to prevent cardiovascular disease was not identified. ATP III did define a triglyceride goal of $<500 \mathrm{mg} / \mathrm{dL}(5.64 \mathrm{mmol} / \mathrm{L})$. to prevent pancreatitis and its complications in patients with severe hypertriglyceridemia defined as fasting triglycerides $>500 \mathrm{mg} / \mathrm{dL}$. Although triglyceride levels $>150 \mathrm{mg} / \mathrm{dL}$ have been associated with increased cardiovascular risk, much of the excess risk disappears after adjustment for low HDL-C and insulin resistance. Clinical trials comparing high- to moderate-dose statin therapy have not found the additional $20 \%$ to $25 \%$ reduction in triglycerides added to the risk reduction expected from the degree of LDL-C reduction, ${ }^{35,39,57}$ nor have trials of fenofibrate and gemfibrozil found a correlation between triglyceride-lowering and cardiovascular event reduction. ${ }^{58}$

"Residual risk" is a term that has been used to describe the fact that patients who have achieved their LDL-C and non-HDL-C goals on statin therapy may still experience a cardiovascular event. These patients often have low HDL-C and elevated levels of triglycerides levels, LDL-C particles, and apo B. While levels of HDL-C and triglycerides remain predictive of cardiovascular risk in patients with LDL-C levels at goal, it is not entirely clear whether the HDL-C increases or triglyceride decreases from drug therapy contribute substantial additional benefit beyond that expected from LDL-C lowering. ${ }^{36,59}$ An evidence-based strategy has yet to be determined for these patients. It should be realized, however, that residual lipid abnormalities are also reflective of the inflammatory state of insulin resistance, and thus may be markers rather than causal factors for the increased cardiovascular risk observed in these patients. ${ }^{60}$

\section{Triglycerides $>500 \mathrm{mg} / \mathrm{dL}$}

In those with triglyceride levels $>500 \mathrm{mg} / \mathrm{dL}$, prevention of pancreatitis is the primary objective. Once triglycerides are $<500 \mathrm{mg} / \mathrm{dL}$, attention can then turn to addressing cardiovascular prevention by lowering LDL-C and non-HDL-C. ${ }^{15}$ In those with severe hypertriglyceridemia, a triglyceride treatment goal of $<500 \mathrm{mg} / \mathrm{dL}$ has been established for the purpose of preventing pancreatitis. Once it has been determined that the patient fasted for at least 8 hours prior to obtaining the blood sample for triglyceride measurement, secondary causes of hypertriglyceridemia should be evaluated since triglyceride levels usually fall to $<500 \mathrm{mg} / \mathrm{dL}$ once these conditions have been treated. Particular attention should be paid to detecting undiagnosed or poorly controlled diabetes or hypothyroidism. All patients should see a dietitian for counseling on a diet very low in fat $(<15 \%)$ and refined carbohydrates, and obese patients should be counseled to lose weight. When triglyceride levels exceed $1000 \mathrm{mg} / \mathrm{dL}$, a triglyceride-lowering drug is usually started simultaneously with diet and lifestyle changes. Fibrates are considered first-line therapy and lower triglycerides by $20 \%$ to $50 \% .{ }^{38}$ Concentrated omega-3 fish oils with 3 to $4 \mathrm{~g}$ of eicosopentanoic and docohexanoic acids are an excellent 
second-line therapy with a similar efficacy profile to fibrates, and may be safer when combined with higher dose statin therapy. ${ }^{61}$ ER niacin can be considered as add-on therapy or in those unable to tolerate fibrates. No efficacy data are available for ER niacin used in patients with triglycerides exceeding $500 \mathrm{mg} / \mathrm{dL}$, but in those with triglyceride levels exceeding $200 \mathrm{mg} / \mathrm{dL}, 25 \%$ to $35 \%$ reductions in triglycerides were obtained above those obtained with simvastatin. Statins also lower triglycerides in a dose-dependent manner, with $25 \%$ to $30 \%$ reductions in triglycerides from atorvastatin 40 to $80 \mathrm{mg}$ and rosuvastatin 20 to $40 \mathrm{mg}$. ${ }^{42}$ Simvastatin, however, has lesser effects on triglycerides, with $15 \%$ to $20 \%$ reductions with simvastatin $40-80 \mathrm{mg}$. Ezetimibe has modest triglyceride-lowering effects. Bile acid sequestrants are contraindicated in these patients since marked exacerbation of hypertriglyceridemia may occur. Once triglyceride levels are $<500 \mathrm{mg} / \mathrm{dL}$, attention can then turn to achieving LDL-C and non-HDL-C goals to reduce cardiovascular risk, as described above.

\section{$\operatorname{Lp}(a)$}

The addition of ER niacin $200 \mathrm{mg}$ lowered Lp(a) by $17 \%$ to $25 \%$ more than simvastatin alone. The significance of this is unclear. Very high levels of Lp(a) are associated with increased cardiovascular risk in some but not all populations, nor has not been shown that reducing $\mathrm{Lp}$ (a) reduces cardiovascular risk. ${ }^{62}$

\section{Cardiovascular endpoint studies}

The addition of niacin or fibrates to statin therapy has been advocated by some to normalize residual HDL-C and triglyceride abnormalities. However, no clinical trial evidence is yet available from long-term morbidity/mortality trials to determine whether pharmacologic strategies directed to these abnormalities are additive to lowering LDL-C and non-HDL-C with statin therapy. Extensive clinical trial evidence has shown that simvastatin and other statins lower the risk of heart attack and stroke in direct proportion to the magnitude of LDL-C reduction. ${ }^{35}$ The only randomized, controlled trial, of niacin monotherapy, the Coronary Drug Project, reported a $17 \%$ reduction in coronary heart disease events over 6.2 years with approximately $2 \mathrm{~g}$ of niacin. ${ }^{63}$ It should be noted this relative reduction in risk is about what would be expected from a $15 \%$ reduction in LD-C with niacin $2 \mathrm{~g}$, the average dose in the trial.

Several trials have evaluated the effect of ER or sustained-release niacin combined with a statin or colestipol on surrogate endpoints of coronary angiographic progression or carotid IMT. Beneficial effects on angiographic progression or carotid IMT were observed over periods of 2 or more years. ${ }^{64-67}$ In the HDL and Atherosclerosis Treatment Trial (HATS), 160 subjects with CHD, low HDL-C, and normal LDL-C were randomized to placebo or a mean dose of simvastatin $13 \mathrm{mg}$ and sustained-release niacin $2.4 \mathrm{~g}$ for 3 years. ${ }^{64}$ The niacin-simvastatin group had a $42 \%$ reduction in LDL-C and a $26 \%$ increase in HDL-C and experienced regression on coronary angiography along with a $92 \%$ reduction in CHD events.

The Arterial Biology for the Investigation of the Treatment Effects of Reducing Cholesterol (ARBITER)-2 study was a 12 month carotid IMT study in 149 subjects that compared a statin to a statin with ER niacin $1000 \mathrm{mg}$ added. ${ }^{68}$ Simvastatin $\geq 20 \mathrm{mg}$ was the statin used by $93 \%$ of subjects. There were no differences in the non-HDL-C or LDL-C levels between the 2 groups, although HDL-C was increased by $21 \%$ and triglycerides were lowered an additional $8 \%$ in the niacin group (Table 1 ). The niacin group had no progression in carotid IMT versus progression in the group on statin monotherapy compared to baseline, although no significant difference between the 2 groups was found at 1 year. A subset of 125 subjects continued into the ARBITER 3 trial and all were treated with ER niacin and a statin for another year. ${ }^{67}$ Among the subjects treated with ER niacin for 24 months, regression of carotid IMT was observed.

Few cardiovascular events were reported in these small surrogate endpoint trials, precluding any definitive conclusions regarding the value of niacin-related lipid changes other than LDL-C reduction for reducing cardiovascular risk. Reductions in coronary heart disease risk varied from $17 \%$ to $92 \%$, although the $95 \%$ confidence intervals were wide and included 1.0 .

Several clinical trials are underway to evaluate the benefit of ER niacin added to background statin therapy. Ongoing clinical trials include the AIM-HIGH trial, which will determine whether the addition of ER niacin to simvastatin will result in additional cardiovascular event reduction independent of the degree of LDL-C-lowering in subjects with established cardiovascular disease. ${ }^{8}$ The HPS-2 THRIVE trial will randomize 20,000 subjects with cardiovascular disease to aggressive LDL-C-lowering using simvastatin with or without ER niacin coformulated with laropiprant. $^{5}$

\section{Areas for future investigation}

The large majority of subjects in the ER niacin-simvastatin database have been middle-aged. Since older individuals 
are at the highest absolute risk of a coronary heart disease or stroke event, more studies of efficacy, safety, and tolerability in the elderly are needed. ${ }^{69}$ Notably, most first cardiovascular events occur after age 75 in women. Efficacy and safety studies are needed in other populations as well. Those with both diabetes and cardiovascular disease are at very high risk of a cardiovascular event and have the potential for the most absolute benefit from very aggressive lipid management. ${ }^{70}$ Those with impaired fasting glucose and metabolic syndrome are also at increased cardiovascular risk, but may also be at increased risk of transitioning to diabetes with niacin. Furthermore, many patients will require the addition of another lipid-lowering agent to high dose statin therapy to achieve very aggressive LDL-C and non-HDL goals.

\section{Conclusions}

ER niacin combined with simvastatin provides an additional option for achieving LDL-C and non-HDL-C goals for cardiovascular prevention. The $2000 \mathrm{mg}$ dose of ER niacin has the greatest benefit for lowering LDL-C and non-HDL-C. ER niacin-simvastatin at both the 1000 and $2000 \mathrm{mg}$ doses is effective for raising HDL-C and lowering triglycerides compared simvastatin monotherapy, although the additive benefit of these changes for reducing cardiovascular events remains to be determined. ER niacin-simvastatin is reasonably well-tolerated by most patients. The muscle and liver safety profile of the combination appears to be similar to that of ER niacin and simvastatin used as monotherapy. Combination of ER niacin with simvastatin has the potential to be safer than some statin-fibrate combinations, although no head-to-head comparison have been performed. ER niacin has an increased rate of hyperglycemia, adverse gastrointestinal effects, and atrial arrhythmias that may alter the benefit-risk ration in at-risk populations. Therefore, the efficacy, safety and tolerability in the elderly, women, those with diabetes, and with the highest doses of statins are needed. Results of ongoing ER niacin morbidity/mortality trials are eagerly awaited.

\section{Disclosures}

Jennifer G Robinson, MD, MPH has received research grants from Abbott, Aegerion, Astra-Zeneca, Bristol-Myers Squibb, Daiichi-Sankyo, Hoffman la Roche, Merck, Merck Schering Plough, Pfizer, and Takeda. She has received speaker honoraria from Merck Schering Plough and has served as a consultant for Astra-Zeneca and Merck Schering Plough.

\section{References}

1. Abbott Laboratories. Simcor (niacin extended-release/simvastatin) [prescribing information]. 2008; Accessed May 5, 2008.

2. Paolini JF, Mitchel YB, Reyes R, et al. Effects of laropiprant on nicotinic acid-induced flushing in patients with dyslipidemia. Am J Cardiol. 2008;101:625-30.

3. Lai E, Wenning L, Crumley T, et al. Pharmacokinetics, pharmacodynamics, and safety of a prostaglandin $\mathrm{D}_{2}$ receptor antagonist. Nature Clin Pharmacol Ther. 2008;83:840-7.

4. Rubic T, Trottmann M, Lorenz R. Stimulation of CD36 and the key effector of reverse choelsterol transport ATP-binding cassette A1 in monocytoid cells by niacin. Biochem Pharmacol. 2004;67:411-9.

5. Oxford University by the Clinical Trial Service Unit. Treatment of HDL to Reduce the Incidence of Vascular Events (HPS2-THRIVE), June 1, 2006 press release.

6. Robinson J, Davidson M. Combination therapy with ezetimibe and simvastatin to acheive aggressive LDL reduction. Expert Rev Cardiovasc Ther. 2006;4:461-76.

7. The Search Collaborative Group. SLCO1B1 variants and statin-induced myopathy - A genomewide study. N Engl J Med. 2008;359:789-99.

8. Robinson JG, Davidson $\mathrm{MH}$. Investigational drugs targeting HDL-C metabolism and reverse cholesterol transport. Fut Lipidol. 2007;2:285-301.

9. Suryadevara RS, Karas RH, Kuvin JT. Use of extended-release niacin in clinical practice. Future Lipidology. 2008;3(1):9-16.

10. Lamon-Fava S, Diffenderfer MR, Barrett PHR, et al. Extended-release niacin alters the metabolism of plasma apolipoprotein (apo) A-I and apoB-containing lipoproteins. Arterioscler Thromb Vasc Biol. 2008;28:1672-8.

11. Zhang L-H, Kamanna VS, Zhang MC, Kashyap ML. Niacin inhibits surface expression of ATP synthase \{beta\} chain in HepG2 cells: implications for raising HDL. J. Lipid Res. 2008;49:1195-201.

12. Ballantyne C, Davidson MH, McKenney JM, Keller LH, Bajorunas DR, Karas RH. Comparison of the efficacy and safety of a combination tablet of niacin extended-release and simvastatin with simvstatin 80 mg montherapy: the SEACOAST II (high dose) study. J Clin Lipidol. 2008;2:79-90.

13. Ballantyne CM, Davidson MH, McKenney J, Keller LH, Bajorunas DR, Karas RH. Comparison of the safety and efficacy of a combination tablet of niacin extended release and simvastatin vs simvastatin monotherapy in patients with increased non-HDL cholesterol (from the SEACOAST I Study). Am J Cardiol. 2008;101:1428-36.

14. Karas RH, Kashyap ML, Knopp RH, Keller LH, Bajorunas DR, Davidson MH. Long-term safety and efficacy of a combination of niacin extended release and simvastatin in patients with dyslipidemia: The OCEANS study. Am J Cardiovasc Drugs. 2008;8:69-81.

15. National Cholesterol Education Panel. Third Report of the National Cholesterol Education Program (NCEP) Expert Panel on Detection, Evaluation, and Treatment of High Blood Cholesterol in Adults (Adult Treatment Panel III) Final Report. Circulation. 2002;106:3143-421.

16. Guyton JR, Bays HE. Safety considerations with niacin therapy. Am J Cardiol. 2007;99(6 Suppl 1):S22-S31.

17. Abbott Laboratories. Niaspan (niacin extended-release) [prescribing information]. March 2008; http://www.rxabbott.com/pdf/niaspan.pdf Accessed August 2008.

18. Davidson MH. Niacin use and cutaneous flushing: Mechanisms and strategies for prevention. Am J Cardiol. 2008;101(8 Supp1 1):S14-S9.

19. Cefali E, Simmons P, Stanek E, McGovern M, Kissling C. Aspirin reduces cutaneous flushing after administration of an optimized extended-release niacin formulation. Int J Clin Pharmacol Ther. 2007;45:78-88.

20. Dunn R, Ford M, Rindone J, Kwiecinski F. Low-dose aspirin and ibuprofen reduce the cutaneous reactions following niacin administration. Am J Ther. 1995;2:478-80.

21. Merck and Co. Zocor (simvastatin) [prescribing information]. 2008; http://www.merck.com/product/usa/pi_circulars/z/zocor/zocor_pi.pdf Accessed June 2008. 
22. Davidson M, Robinson JG. Safety of aggressive lipid management. J Am Coll Cardiol. 2007;49:1753-62.

23. Cohen D, Anania F, Chalasani N. An assessment of statin safety by hepatologists. Am J Cardiol. 2006;97(8 Suppl 1):S77-81.

24. Thompson PD, Clarkson PM, Rosenson RS. An assessment of statin safety by muscle experts. Am J Cardiol. 2006;97(8 Suppl 1): S69-S76.

25. Abbott Laboratories. Advicor (extended-release niacin) [prescribing information]. August 2007; http://www.rxabbott.com/pdf/advicor.pdf. Accessed June 2008.

26. Alsheikh-Ali AA, Karas RH. The safety of niacin in the US Food and Drug Administration Adverse Event Reporting database. Am J Cardiol. 2008;101(8 Suppl 1):S9-S13.

27. Heart Protection Study Collaborative Group. MRC/BHF Heart Protection Study of cholesterol lowering with simvastatin in 20,536 high-risk individuals: a randomised placebo-controlled trial. Lancet. 2002;360:7-22.

28. Graham DJ, Staffa JA, Shatin D, et al. Incidence of hospitalized rhabdomyolysis in patients treated with lipid-lowering drugs. JAMA. 2004;292:2585-90.

29. Prueksaritanont T, Zhao JJ, Ma B, et al. Mechanistic studies on metabolic interactions between gemfibrozil and statins. J Pharmacol Exp Ther. 2002;301:1042-51.

30. Goosen TC, Bauman JN, Davis JA, et al. Atorvastatin glucuronidation is minimally and non-selectively inhibited by the fibrates gemfibrozil, fenofibrate and fenofibric acid. Drug Metab Dispos. 2007; Epub April 30, 2007:dmd.107.015230.

31. Neuvonen PJ, Niemi M, Backman JT. Drug interactions with lipid-lowering drugs: Mechanisms and clinical relevance. Clin Pharmacol Ther. 2006;80:565-81.

32. Elam MB, Hunninghake DB, Davis KB, et al. Effect of niacin on lipid and lipoprotein levels and glycemic control in patients with diabetes and peripheral arterial disease: The ADMIT Study: A randomized trial. JAMA. 2000;284:1263-70.

33. Canner PL, Furberg CD, Terrin ML, McGovern ME. Benefits of niacin by glycemic status in patients with healed myocardial infarction (from the Coronary Drug Project). Am J Cardiol. 2005;95:254-7.

34. Canner PL, Furberg CD, McGovern ME. Benefits of niacin in patients with versus without the metabolic syndrome and healed myocardial infarction (from the Coronary Drug Project). Am J Cardiol. 2006;97:477-9.

35. Cholesterol Treatment Trialists' (CTT) Collaborators. Efficacy and safety of cholesterol-lowering treatment: prospective meta-analysis of data from 90,056 participants in 14 randomised trials of statins. Lancet. 2005;366:1267-78.

36. Robinson JG, Smith B, Maheshwari N, Schrott H. Pleiotropic effects of statins: Benefit beyond cholesterol reduction? A meta-regression analysis. J Am Coll Cardiol. 2005;46:1855-62.

37. Grundy SM, Cleeman JI, Merz CNB, et al. Implications of recent clinical trials for the National Cholesterol Education Program Adult Treatment Panel III guidelines. Circulation. 2004;110:227-39.

38. Smith JSC, Allen J, Blair SN, et al. AHA/ACC guidelines for secondary prevention for patients with coronary and other atherosclerotic vascular disease: 2006 update: Endorsed by the National Heart, Lung, and Blood Institute. J Am Coll Cardiol. 2006;47:2130-9.

39. LaRosa JC, Grundy SM, Waters DD, et al. Intensive lipid lowering with atorvastatin in patients with stable coronary disease. $N$ Engl $J$ Med. 2005;352:1425-35.

40. AstraZeneca Pharmaceuticals. Crestor (rosuvstatin calcium) [prescribing information]. January 2007; http://www.astrazeneca-us.com/pi/crestor. pdf. Accessed February 2007.

41. Pfizer Inc. Lipitor (atorvastatin calcium) [prescribing information]. November 2007; http://www.pfizer.com/files/products/uspi_lipitor. pdf. Accessed June 2008 .

42. Jones PH, Davidson MH, Stein EA, et al. Comparison of the efficacy and safety of rosuvastatin versus atorvastatin, simvastatin, and pravastatin across doses (STELLAR Trial). Am J Cardiol. 2003;92:152-60.
43. Daiichi Sankyo I. Welchol (coleselvelam hydrochloride) [prescribing information]. December 2005; http://www.welchol.com/pdf/Welchol_ PI.pdf. Accessed May 5, 2008.

44. Wagner AM, Jorba O, Bonet R, Ordonez-Llanos J, Perez A. Efficacy of atorvastatin and gemfibrozil, alone and in low dose combination, in the treatment of diabetic dyslipidemia. J Clin Endocrinol Metab. 2003; $88: 3212-7$.

45. Athyros VG, Papageorgiou AA, Athyrou VV. Demitriadis DS, Kontopoulos AG. Atorvastatin and micronized fenofibrate alone and in combination in type 2 diabetes with combined hyperlipidemia. Diab Care. 2002;25:1198-202.

46. Durrington PN, Tuomilehto J, Hamann A, Kallend D, Smith K. Rosuvastatin and fenofibrate alone and in combination in type 2 diabetes patients with combined hyperlipidaemia. Diab Res Clin Pract. 2004;64:137-51.

47. Kastelein JJP, Akdim F, Stroes ESG, et al. Simvastatin with or without ezetimibe in familial hypercholesterolemia. $N$ Engl J Med. 2008; 358:1431-43.

48. Smilde TJ, van Wissen S, Awollersheim H, Trip MD, Kastelein JJP, Stalenhoef AFH. Effect of aggressive versus conventional lipid lowering on atherosclerosis progression in familial hypercholesterolemia (ASAP): a prospective, randomised, double-blind trial. Lancet. 2001;357:577-81.

49. Underhill HR, Yuan C, Zhao X-Q, et al. Effect of rosuvastatin therapy on carotid plaque morphology and composition in moderately hypercholesterolemic patients: A high-resolution magnetic resonance imaging trial. Am Heart J. 2008;155:584.e581-584.e588.

50. Johnson HM, Douglas PS, Srinivasan SR, et al. Predictors of carotid intima-media thickness progression in young adults: The Bogalusa Heart Study. Stroke. 2007;38:900-5.

51. van Wissen S, Smilde TJ, Trip MD, Stalenhoef AFH, Kastelein JJP. Long-term safety and efficacy of high-dose atorvastatin treatment in patients with familial hypercholesterolemia. Am JCardiol. 2005;95:264-6.

52. Loftus P, Merck halts study of experimental cholesterol drug. Wall Street Journal. 2008; May 22.

53. Rossebo AB, Pedersen TR, Boman K, et al. Intensive lipid lowering with simvastatin and ezetimibe in aortic stenosis. N Engl J Med. 2008; 359:1343-56.

54. Peto R, Emberson J, Landray M, et al. Analyses of cancer data from three ezetimibe trials. N Engl J Med. 2008;359:1357-66.

55. Kastelein JJP, van der Stieg W, Holme I, et al. Lipids, apoliproteins, and their ratios in relation to cardiovascular events with statin treatment. Circulation. 2008;117:3002-9.

56. Barter PJ, Caulfield M, Eriksson M, et al. Effects of torcetrapib in patients at high risk for coronary events. $N$ Engl $J$ Med. 2007;357:2109-22.

57. Pedersen TR, Faergeman O, Kastelein JJP, et al. High-dose atorvastatin vs usual-dose simvastatin for secondary prevention after myocardial infarction: The IDEAL Study: A randomized controlled trial. JAMA. 2005;294:2437-45.

58. Robinson JG. Should we use PPAR agonists to reduce cardiovascular risk? PPAR Res. 2008; doi:10.1155/2008/891425.

59. Barter P, Gotto AM, LaRosa JC, et al. HDL cholesterol, very low levels of LDL cholesterol, and cardiovascular events. N Engl J Med. 2007; 357:1301-10.

60. Mozaffarian D, Wilson PWF, Kannel WB. Beyond established and novel risk factors: Lifestyle risk factors for cardiovascular disease. Circulation. 2008;117:3031-8.

61. Robinson JG, Stone NJ. Antiatherosclerotic and antithrombotic effects of omega-3 fatty acids. Am J Cardiol. 2006;98(4 Suppl 1):39-49.

62. Marcovina SM, Koschinsky ML, Albers JJ, Skarlatos S. Report of the National Heart, Lung, and Blood Institute workshop on lipoprotein(a) and cardiovascular disease: Recent advances and future directions. Clin Chem. 2003;49:1785-96.

63. Coronary Drug Project. Clofibrate and niacin in coronary heart disease. JAMA. 1975;231:360-80. 
64. Brown BG, Zhao X-Q, Chait A, et al. Simvastatin and niacin, antioxidant vitamins, or the combination for the prevention of coronary disease. N Engl J Med. 2001;345:1583-92.

65. Brown MDPBG, Bardsley MDJ, Poulin BSD, Hillger PLA. Moderate dose, three-drug therapy with niacin, lovastatin, and colestipol to reduce low-density lipoprotein cholesterol $<100 \mathrm{mg} / \mathrm{dl}$ in patients with hyperlipidemia and coronary artery disease. Am J Cardiol. 1997;80:111-5.

66. Cashin-Hemphill L, Mack W, Pogoda J, Sanmarco M, Azen S, Blankenhorn D. Beneficial effects of colestipol-niacin on coronary atherosclerosis: A 4-year follow-up. JAMA. 1990;264:3013-7.

67. Taylor A, Lee H, Sullenberger L. The effect of 24 months of combination statin and extended-release niacin on carotid intima-media thickness: ARBITER 3. Curr Opin Med Res Opin. 2006;22:2243-50.
68. Taylor AJ, Sullenberger LE, Lee HJ, Lee JK, Grace KA. Arterial Biology for the Investigation of the Treatment Effects of Reducing Cholesterol (ARBITER) 2: A double-blind, placebo-controlled study of extended-release niacin on atherosclerosis progression in secondary prevention patients treated with statins. Circulation. 2004; 110:3512-7.

69. Robinson JG, Bakris G, Torner J, Stone NJ, Wallace R. Is it time for a cardiovascular primary prevention trial in the elderly? Stroke. 2007; 38:441-50.

70. Robinson JG, Stone NJ. Identifying patients for aggressive cholesterol lowering: The risk curve concept. Am J Cardiol. 2006;98:1405-8. 
